\title{
Effect of Formulation Variables on Dissolution of Water-Soluble Drug from Polyelectrolyte Complex Beads
}

\author{
M. A. Saleem ${ }^{1,2, *}$, Divesh R Kotadia ${ }^{1}$, and Raghavendra V. Kulkarni ${ }^{3, *}$ \\ ' Department of Pharmaceutics, Luqman College of Pharmacy, Old Jevargi Road, Gulbarga, India \\ ${ }^{2}$ Department of Biotechnology, Achariya Nagarjuna University, Nagarjuna Nagar, India \\ ${ }^{3}$ Department of Pharmaceutical Technology, BLDEA's College of Pharmacy, Bijapur 586103, India
}

\begin{abstract}
This study was planned to develop chitosan-based polyelectrolyte complex (PEC) beads for the prolonged release of the water-soluble drug, verapamil $\mathrm{HCl}(\mathrm{VPL})$. The PEC beads were prepared by an ionic gelation method using positively charged chitosan $(\mathrm{CH})$ and negatively charged sodium alginate (ALG), carboxymethylcellulose sodium (CMC), and k-carrageenan (CAR). The surface morphology was investigated by scanning electron microscopy (SEM), and PEC formation was confirmed by differential scanning calorimetry (DSC) and Fourier transform infrared (FTIR) spectroscopy. Gel beads were evaluated for particle size, drug entrapment efficiency, swelling behavior, and in vitro release. The SEM study confirmed that spherical or disc-shaped beads were formed by changing the counterion and $\mathrm{pH}$ of the coagulation medium. DSC and FTIR spectroscopy confirmed the PEC formation. The mean particle size was 556-896 $\mu \mathrm{m}$, and drug entrapment efficiency was more than $80 \%$. The beads showed $\mathrm{pH}$-sensitive swelling with less swelling in hydrochloric acid buffer $(\mathrm{pH} \mathrm{1.2)} \mathrm{and} \mathrm{more}$ swelling in phosphate buffer $(\mathrm{pH}$ 7.4). The in vitro release of $\mathrm{VPL}$ was very slow in $\mathrm{HCl}$ buffer as compared with phosphate buffer. The concentration of chitosan, anionic polymers, and the $\mathrm{pH}$ of the coagulation medium significantly affected the size, entrapment efficacy, swelling, and release pattern of PEC beads.
\end{abstract}

\section{INTRODUCTION}

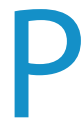

olycationic chitosan $(\mathrm{CH})$ is prepared through deacetylation of chitin. Chitosan is an important biopolymer having wide pharmaceutical application (1). Chitosan polyelectrolyte complexes (PEC) are ideal substitutes for covalently cross-linked hydrogels. The formation of a PEC requires only polycationic and polyanionic polymers without catalysts or initiators, and the reaction is generally performed in aqueous solution, which is the main advantage over covalently cross-linked polymeric networks. Therefore PEC offers biocompatibility and avoids the purification step to minimize the toxicity associated with the unreacted covalent cross-linking agents before administration (2-6). The electrostatic attraction between the amino groups of $\mathrm{CH}$ and the carboxylic-sulfate groups of anionic polymers is the main interaction leading to the formation of the PEC (7). PECs can be cross-linked by the addition of ions to form ionically cross-linked systems, for instance, calcium ions can be added to alginate (8), and pectin (9) and aluminum ions can be added to carboxymethylcellulose (4). Chitosanbased PECs are well-tolerated systems and can be used in various applications such as drug delivery systems (10).

Verapamil hydrochloride (VPL) is a freely water-soluble calcium channel blocker used in the treatment of angina pectoris, hypertension, and supraventricular tachyarrhythmias $(11,12)$. Upon oral administration, $90 \%$ of drug is absorbed from the gastrointestinal tract, but it has low bioavailability of $22 \%$ with a biological half-life of $4 \pm 1.5 \mathrm{~h}$ (13).

${ }^{*}$ Corresponding author.
In the present study, polyelectrolyte complex beads were prepared using $\mathrm{CH}$ (cationic polymer) along with three anionic polymers (sodium alginate, carboxymethylcellulose sodium, and k-carrageenan) for prolonged release of the water-soluble drug, VPL. The effect of the concentrations of $\mathrm{CH}$ and counter ions and the $\mathrm{pH}$ of the coagulation medium on the formation and performance of PEC beads was studied.

\section{MATERIALS AND METHODS Materials}

Verapamil $\mathrm{HCl}$ was a kind gift sample from Unicure Pvt. Ltd. (India) and Torrent Pharmaceuticals Ltd. (India). Chitosan (minimum $80 \%$ deacetylated) was a gift sample from Mahtani Chitosan Pvt. Ltd. (India). Sodium alginate (ALG) was obtained from Snap Natural and Alginate Pvt. Ltd. (India). $\kappa$-Carrageenan (CAR) was obtained from Sigma-Aldrich (USA). Carboxymethylcellulose sodium (CMC), calcium chloride, aluminum chloride, potassium chloride, and glacial acetic acid were obtained from SD Fine Chem Ltd. (India).

\footnotetext{
Methods

Preparation of PEC Beads

The preparation details of PEC beads are given in Table 1. PEC beads were prepared by an ionic gelation method using varied concentrations $(0.5 \%, 1 \%$, and $1.5 \% \mathrm{w} / \mathrm{w})$ of $\mathrm{CH}$ along with fixed concentrations of ALG, CMC, and CAR in the presence of calcium, aluminum, and potassium as counter ions. The amount of VPL was kept constant (1\% $w / v)$. Homogeneous aqueous solutions of $\mathrm{CH}$ and calcium chloride/aluminum chloride/potassium chloride were
} 
Table 1. Formulation Details of Chitosan-Based Polyelectrolyte Complex Beads

\begin{tabular}{|c|c|c|c|c|c|c|c|c|}
\hline Code & VPL (\% w/v) & $\mathrm{CH}(\% \mathrm{w} / \mathrm{v})$ & ALG (\%w/v) & CMC (\%w/v) & CAR (\% w/v) & $\mathrm{CaCl}_{2}(\% \mathrm{w} / \mathrm{v})$ & $\mathrm{AlCl}_{3}(\% \mathrm{w} / \mathrm{v})$ & $\mathrm{KCl}(\% \mathrm{w} / \mathrm{v})$ \\
\hline $\mathrm{CAC}_{\mathrm{a}}$ & 1 & 0.5 & 3 & -- & -- & 2 & -- & -- \\
\hline $\mathrm{CACl}_{\mathrm{b}}$ & 1 & 0.5 & 3 & -- & -- & 2 & -- & -- \\
\hline $\mathrm{CAC2}_{\mathrm{a}}$ & 1 & 1 & 3 & -- & -- & 2 & -- & -- \\
\hline$C A C 2 b$ & 1 & 1 & 3 & -- & -- & 2 & -- & -- \\
\hline $\mathrm{CAC}_{\mathrm{a}}$ & 1 & 1.5 & 3 & -- & -- & 2 & -- & -- \\
\hline $\mathrm{CAC}_{\mathrm{b}}$ & 1 & 1.5 & 3 & -- & -- & 2 & -- & -- \\
\hline $\mathrm{CAA} 1_{\mathrm{a}}$ & 1 & 0.5 & 3 & -- & -- & -- & 2 & -- \\
\hline$C A A 1_{b}$ & 1 & 0.5 & 3 & -- & -- & -- & 2 & -- \\
\hline $\mathrm{CAA}_{\mathrm{a}}$ & 1 & 1 & 3 & -- & -- & -- & 2 & -- \\
\hline$C A A 2_{b}$ & 1 & 1 & 3 & -- & -- & -- & 2 & -- \\
\hline $\mathrm{CAA3}_{\mathrm{a}}$ & 1 & 1.5 & 3 & -- & -- & -- & 2 & -- \\
\hline $\mathrm{CAA}_{\mathrm{b}}$ & 1 & 1.5 & 3 & -- & -- & -- & 2 & -- \\
\hline $\mathrm{CC}_{\mathrm{a}}$ & 1 & 0.5 & -- & 3 & -- & -- & 2 & -- \\
\hline $\mathrm{CC}_{\mathrm{b}}$ & 1 & 0.5 & -- & 3 & -- & -- & 2 & -- \\
\hline $\mathrm{CC}_{\mathrm{a}}$ & 1 & 1 & -- & 3 & -- & -- & 2 & -- \\
\hline $\mathrm{CC} 2_{\mathrm{b}}$ & 1 & 1 & -- & 3 & -- & -- & 2 & -- \\
\hline $\mathrm{CC}_{\mathrm{a}}$ & 1 & 1.5 & -- & 3 & -- & -- & 2 & -- \\
\hline $\mathrm{CC}_{\mathrm{b}}$ & 1 & 1.5 & -- & 3 & -- & -- & 2 & -- \\
\hline $\mathrm{CK}_{\mathrm{a}}$ & 1 & 0.5 & -- & - & 2.5 & -- & -- & 4 \\
\hline $\mathrm{CK} 1_{\mathrm{b}}$ & 1 & 0.5 & -- & -- & 2.5 & -- & -- & 4 \\
\hline $\mathrm{CK} 2_{\mathrm{a}}$ & 1 & 1 & -- & -- & 2.5 & -- & -- & 4 \\
\hline $\mathrm{CK} 2_{\mathrm{b}}$ & 1 & 1 & -- & -- & 2.5 & -- & -- & 4 \\
\hline $\mathrm{CK}_{\mathrm{a}}$ & 1 & 1.5 & -- & -- & 2.5 & -- & -- & 4 \\
\hline $\mathrm{CK}_{\mathrm{b}}$ & 1 & 1.5 & -- & -- & 2.5 & -- & -- & 4 \\
\hline
\end{tabular}

used as coagulation media, and the $\mathrm{pH}$ was adjusted to 2 or 4 . The $\mathrm{CH}$ was dissolved in acetic acid solution (1\% $\mathrm{v} / \mathrm{v})$, and the $\mathrm{pH}$ was adjusted using $1 \mathrm{M} \mathrm{HCl}$ and $1 \mathrm{M}$ $\mathrm{NaOH}$. The mixtures of ALG/CMC/CAR and drug in distilled water were dropped through a 30-gauge needle into the coagulation media with appropriate mechanical stirring. The beads were then filtered, washed, and dried at room temperature for $24 \mathrm{~h}$.

\section{Scanning Electron Microscopy (SEM)}

The surface morphology of the beads was examined by SEM (SEM LEO 14 SSVP, Cambridge, UK) mounted with a digital camera. All the samples were sputter-coated with gold-palladium before observation and mounted directly onto the SEM sample holder. Micrographs were obtained using an XL 30 field emission environmental microscope with acceleration voltages of 15 and $20 \mathrm{kv}$.

\section{Differential Scanning Calorimetry (DSC)}

DSC thermograms were obtained using an automatic thermal analyzer system (Perkin Elmer DSC Instrument, Japan). Temperature calibration was performed using in- dium as the standard. Samples were crimped in a standard aluminum pan and heated from 50 to $300^{\circ} \mathrm{C}$ at a heating rate of $10^{\circ} \mathrm{C} / \mathrm{min}$ under constant purging of dry nitrogen at $30 \mathrm{~mL} / \mathrm{min}$. An empty pan, sealed in the same manner as the samples, was used as a reference.

Fourier Transformation Infrared (FTIR) Spectroscopy

Drug-polymer and polymer-polymer interactions were studied by FTIR spectrometer (Perkin-Elmer Spectrum-100, Japan). A potassium bromide ( $\mathrm{KBr}$ ) disc was prepared by mixing the sample with dry $\mathrm{KBr}(2 \% \mathrm{w} / \mathrm{w})$, grinding the mixture into a fine powder using an agate mortar, and then compressing it into a disc in a hydraulic press at a pressure of 10,000 psi. Each $\mathrm{KBr}$ disc was scanned 16 times at $2 \mathrm{~cm}^{-1} / \mathrm{sec}$ at a resolution of $4 \mathrm{~cm}^{-1} / \mathrm{sec}$ using cosine apodization. The characteristic peaks were recorded.

\section{Particle Size}

Particle size and mean bead diameter measurements were carried out with an optical microscope. A stage micrometer was used to calculate the calibration factor. The 10-division of the stage micrometer was matched with 
the division of an ocular disc, and the calibration factor was calculated. Particle size was calculated by multiplying the number of divisions of the ocular disc that the particle occupied by the calibration factor. Fifty randomly chosen beads were taken to measure their individual sizes.

\section{Drug Entrapment Efficiency}

Accurately weighed beads equivalent to $100 \mathrm{mg}$ of drug were incubated in $100 \mathrm{~mL}$ of $\mathrm{pH} 7.4$ phosphate buffer solution for $24 \mathrm{~h}$ at $37^{\circ} \mathrm{C}$. After $24 \mathrm{~h}$, the mixture was stirred for $5 \mathrm{~min}$ and filtered. After suitable dilution (10 times), drug content in the filtrate was analyzed spectrophotometrically at $278 \mathrm{~nm}$ (Shimadzu-1700 UV-vis spectrophotometer) against a blank. The blank solution was prepared in the same manner as above using beads without the drug. The drug entrapment efficiency was calculated using the following equation:

\begin{tabular}{|c|c|c|}
\hline \multirow{2}{*}{$\begin{array}{l}\text { Drug entrapment } \\
\text { efficiency }\end{array}$} & \multirow{2}{*}{$=$} & $\begin{array}{l}\text { Experimental } \\
\text { drug content }\end{array}$ \\
\hline & & $\begin{array}{l}\text { Theoretical drug } \\
\text { content }\end{array}$ \\
\hline
\end{tabular}

\section{Swelling Studies}

A swelling study of the beads was performed in $\mathrm{pH} 1.2$ $\mathrm{HCl}$ buffer solution for the initial $2 \mathrm{~h}$ and in $\mathrm{pH} 7.4$ phosphate buffer solution for the next $6 \mathrm{~h}$ to simulate the gastric environment. Accurately weighed amounts of beads were immersed in the respective solutions, and at fixed time intervals (every hour), the beads were separated from the medium, immediately wiped gently with paper, and reweighed. The dynamic weight change of the beads with respect to time was calculated according to the formula

$$
\begin{aligned}
& \text { Percent weight } \\
& \text { change }
\end{aligned}=\frac{W_{\mathrm{s}}-W_{\mathrm{i}}}{W_{\mathrm{i}}} \times 100
$$

where $W_{s}$ is the weight of beads in the swollen state and $W_{\mathrm{i}}$ is the initial weight of beads.

\section{In Vitro Dissolution Study}

The in vitro release of VPL from beads was carried out for $8 \mathrm{~h}$ using a USP Apparatus 2 paddle type dissolution tester (Electrolab, Mumbai) containing $900 \mathrm{~mL}$ of dissolution medium maintained at $37 \pm 0.5^{\circ} \mathrm{C}$ with a stirring speed of $50 \mathrm{rpm}$. For the first $2 \mathrm{~h}, \mathrm{pH} 1.2 \mathrm{HCl}$ buffer was used as dissolution medium, then it was replaced with $\mathrm{pH}$ 7.4 phosphate buffer for a further $6 \mathrm{~h}$. At 1-h intervals, 5 $\mathrm{mL}$ of solution was withdrawn and analyzed spectrophotometrically for drug content at $278 \mathrm{~nm}$. The volume of the dissolution medium was adjusted to $900 \mathrm{~mL}$ at every sampling time by replacement with $5 \mathrm{~mL}$ of the same medium.
The spectrophotometric method was validated. A stock standard solution was prepared by dissolving 100-mg samples of VPL, accurately weighed, in $100 \mathrm{~mL}$ buffer solutions of $\mathrm{pH} 1.2$ and 7.4. The stock standard solution was scanned in the UV spectrophotometer over a wavelength range of $200-300 \mathrm{~nm}$. The maximum absorbance was found at $278 \mathrm{~nm}$. Hence, the same wavelength was used for the determination of VPL. Aliquots of the stock standard solution were diluted 1:100 with respective buffer solutions to give stock solutions of $10 \mu \mathrm{g} / \mathrm{mL}$. Serial dilutions were made to give final concentrations of 5,10 , $15,20,25$, and $30 \mu \mathrm{g} / \mathrm{mL}$. The absorbances of these solutions were measured at $278 \mathrm{~nm}$ against a suitable blank. The procedure was performed in triplicate to validate the calibration curve.

\section{RESULTS AND DISCUSSION Formation of PEC Beads}

PEC beads were prepared by the interaction of positively charged $\mathrm{CH}$ with negatively charged ALG, CMC, and $\mathrm{CAR}$, and the $\mathrm{pH}$ of the coagulation solution was varied between $\mathrm{pH} 2$ and 4. Various counterions like $\mathrm{Ca}^{2+}, \mathrm{Al}^{3+}$, and $\mathrm{K}^{+}$were added to improve the mechanical strength of the beads. The electrostatic attraction between the amino $\left(-\mathrm{NH}_{3}{ }^{+}\right)$groups of $\mathrm{CH}$ and the carboxylic $\left(-\mathrm{COO}^{-}\right)$groups of $A L G$ and $C M C$ and the sulfonic $\left(-\mathrm{SO}_{4}^{-}\right)$groups of CAR resulted into the formation of polyelectrolyte complexes. The $\mathrm{CH}$ forms the outer layer of the beads, and higher concentrations of $\mathrm{CH}$ provide a higher charge density of amino groups. This results in higher cross-linking of PEC and thus produces a stronger PEC membrane. Only anionic polymer that did not interact completely with $\mathrm{CH}$ was present in the core of the beads.

\section{Morphology of PEC Beads}

The $\mathrm{CH} / \mathrm{ALG}$ beads prepared using $\mathrm{CaCl}_{2}$ were spherical with rough surfaces (Figure $1 \mathrm{~A}$ ). When $\mathrm{AlCl}_{3}$ was used as counterion, the beads were smoother but flattened and disc-shaped with collapsed centers (Figure 1B). The CH/ $\mathrm{CMC}$ beads prepared at $\mathrm{pH} 2$ were spherical with a rough and dense surface (Figure 1C), and at $\mathrm{pH} 4$, beads were flattened and disc-shaped with collapsed centers along with surface folding (Figure 1D). CH/CAR beads were spherical with smoother surfaces (Figure 1E).

\section{Differential Scanning Calorimetry}

The DSC thermograms of VPL, CH, ALG, CMC, CAR, and VPL-loaded CH/ALG, CH/CMC, and CH/CAR beads are shown in Figure 2. The thermogram of VPL exhibits a sharp endothermic peak at $146^{\circ} \mathrm{C}$. The thermograms of $\mathrm{CH}, \mathrm{ALG}$, CMC, and CAR exhibit endothermic peaks at $86,87,72$, and $81^{\circ} \mathrm{C}$, respectively, due to evaporation of absorbed water. The thermograms of $\mathrm{CH}$ also show an exothermic peak at $262^{\circ} \mathrm{C}$, which indicates the onset of degradation. Whereas ALG shows two exothermic peaks at $251^{\circ} \mathrm{C}$ and $265^{\circ} \mathrm{C}$, similarly CMC and CAR show exothermic peaks at $250^{\circ} \mathrm{C}$ 

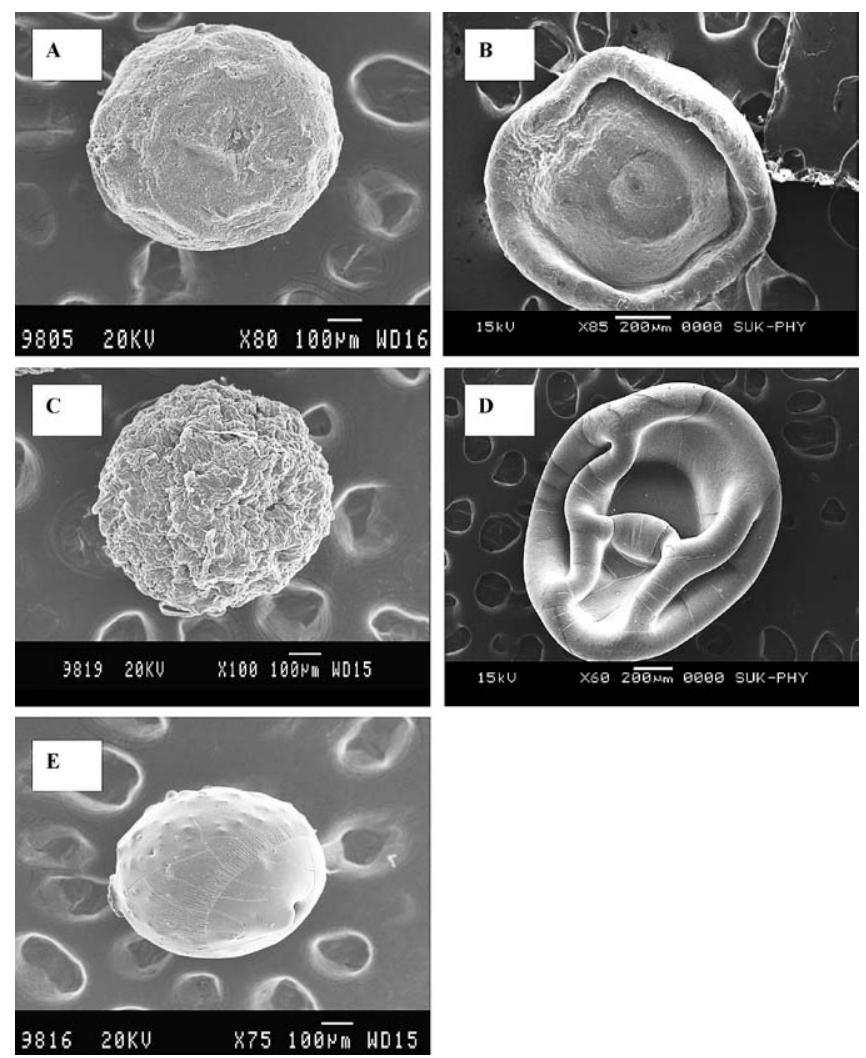

Figure 1. Scanning electron micrographs of VPL-loaded CH/ALG beads formulated with (A) $\mathrm{CaCl}_{2}$ and (B) $\mathrm{AlCl} \mathrm{Cl}_{3} \mathrm{CH} / \mathrm{CMC}$ beads formulated at coagulation medium (C) $\mathrm{pH} 2$ and (D) $\mathrm{pH} 4$; and (E) CH/CAR beads.

and $265^{\circ} \mathrm{C}$, respectively. In DSC thermograms of VPLloaded $\mathrm{CH} / \mathrm{ALG}$ beads, the peak corresponding to drug was shifted from $146^{\circ} \mathrm{C}$ to $179^{\circ} \mathrm{C}$; the peaks corresponding to $\mathrm{CH}$ and ALG disappeared, and a coupled peak at $193^{\circ} \mathrm{C}$ appeared. For VPL-loaded $\mathrm{CH} / \mathrm{CMC}$ beads, two endothermic peaks were observed at $179^{\circ} \mathrm{C}$ and $187^{\circ} \mathrm{C}$. The thermogram of VPL-loaded $\mathrm{CH} / \mathrm{CAR}$ beads does not show any distinct peak but has a less intense exothermic peak at $245^{\circ} \mathrm{C}$. The results of drug-loaded beads suggest that a polyelectrolyte complex is formed between $\mathrm{CH}$ and $\mathrm{ALG}, \mathrm{CMC}$, and CAR during preparation. However, the disappearance or shifting of the VPL peaks indicates that most of the drug was uniformly dispersed at the molecular level in the beads or it may be caused by the electrostatic interaction between charged VPL and polymers (11).

\section{Fourier Transformation Infrared Spectroscopy}

The FTIR spectra of VPL, CH, ALG, CMC, CAR, and VPLloaded $\mathrm{CH} / \mathrm{ALG}, \mathrm{CH} / \mathrm{CMC}$, and $\mathrm{CH} / \mathrm{CAR}$ beads are shown in Figure 3. The FTIR spectrum of VPL exhibits a sharp characteristic absorption peak at $2236 \mathrm{~cm}^{-1}$ confirming the presence of $-\mathrm{C} \equiv \mathrm{N}$ groups in the drug molecule. An absorption peak at $2837 \mathrm{~cm}^{-1}$ is due to $\mathrm{C}-\mathrm{H}$ stretching of the VPL methoxy groups. The other characteristic peaks are in concurrence with the structure of the drug. Since the $\mathrm{CH}$,

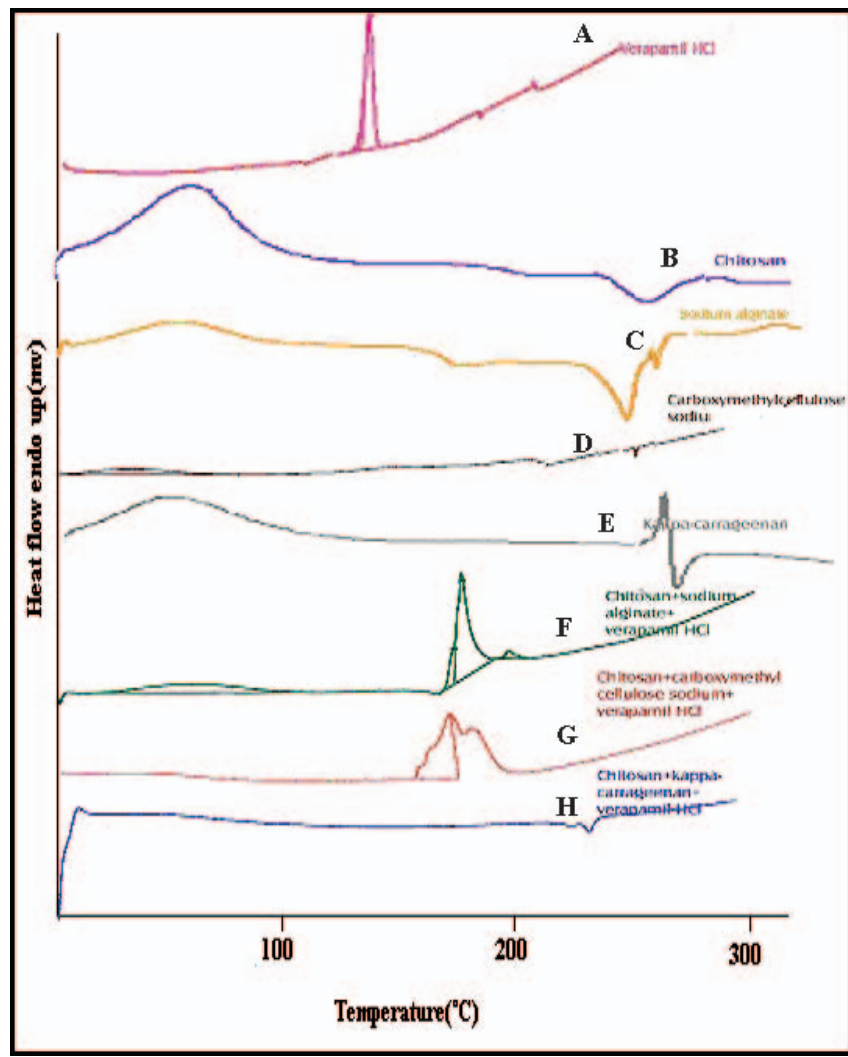

Figure 2. DSC thermograms of (A) VPL, (B) chitosan, (C) ALG, (D) CMC, (E) CAR, (F) CH/ALG beads, (G) CH/CMC beads, and (H) CH/CAR beads.

ALG, CMC, and CAR are carbohydrate polymers, they have $-\mathrm{OH}$ groups in their structure, which was confirmed by the broad peak between $3100-3600 \mathrm{~cm}^{-1}$. The FTIR spectrum of $\mathrm{CH}$ also shows a weak peak of $\mathrm{C}-\mathrm{H}$ stretching at $2875 \mathrm{~cm}^{-1}$ and a bending vibration peak of the $\mathrm{N}-\mathrm{H}$ of non-acylated 2-amino glucose primary amines at $1534 \mathrm{~cm}^{-1}$. The FTIR spectra of ALG and CMC show broad peaks near $1700 \mathrm{~cm}^{-1}$, confirming the presence of a - $\mathrm{COO}^{-}$group in their structures. The spectrum of CAR shows a broad absorption peak around $1350 \mathrm{~cm}^{-1}$, which is due to sulphonic acid $\left(-\mathrm{SO}_{4}^{-}\right)$ groups. In the FTIR spectrum of VPL-loaded CH/ALG beads, the peak at $1700 \mathrm{~cm}^{-1}$ (which was observed in ALG spectra) is coupled to form a broad peak near $2200-2400 \mathrm{~cm}^{-1}$. In the FTIR spectrum of VPL-loaded $\mathrm{CH} / \mathrm{CMC}$ beads, the peak observed at $1200 \mathrm{~cm}^{-1}$ in CMC is shifted to $750-800 \mathrm{~cm}^{-1}$. In the spectrum of $\mathrm{CH} / \mathrm{CAR}$ beads, the peak at $2200 \mathrm{~cm}^{-1}$, which was observed in CAR spectrum, disappeared. It also shows an absorption peak around $1600-1700 \mathrm{~cm}^{-1}$, which is not observed in the spectrum of $\mathrm{CH}$ and CAR. This is evidence for the formation of polyelectrolyte complexes between $\mathrm{CH}$ and $\mathrm{ALG}, \mathrm{CMC}$, and CAR during preparation. However, the characteristic peaks of VPL have changed or shifted in the spectra of the formulations. In the spectrum of VPL-loaded CH/ALG beads, the broad peak around 2500 $\mathrm{cm}^{-1}$ is not observed along with sharp peaks at $2300 \mathrm{~cm}^{-1}$ and $1600-1700 \mathrm{~cm}^{-1}$. These peaks are absent in spectrum of 
VPL. Similarly, in the spectrum of $\mathrm{CH} / \mathrm{CAR}$ beads, two broad peaks are observed at $2900 \mathrm{~cm}^{-1}$ and $2500 \mathrm{~cm}^{-1}$. These peaks are absent in the spectrum of VPL. This might be due to the electrostatic interaction of VPL with ALG, CMC, and CAR during the formation of PECs.

\section{Size of the Beads}

The size of the beads is summarized in Table 2. Bead size was influenced by the concentrations of $\mathrm{CH}$ and counterions and the $\mathrm{pH}$ of coagulation medium. The orifice of the needle and the rate of pouring the polymeric solution into the counter ion solution were fixed. The mean particle size of $\mathrm{CH} / \mathrm{ALG}$ beads prepared with $\mathrm{CaCl}_{2}$ was between 556 and $739 \mu \mathrm{m}$, whereas formulations containing $\mathrm{AlCl}_{3}$ were in the range of 705-865 $\mu \mathrm{m}$. The particle size range for $\mathrm{CH} / \mathrm{CMC}$ beads was $698-896 \mu \mathrm{m}$ and for $\mathrm{CH} / \mathrm{CAR}$ beads it was 683-889 $\mu \mathrm{m}$. All preparations showed an increase in size as the concentration of $\mathrm{CH}$ increased, which was due to extra coating of $\mathrm{CH}$ with increasing concentration (12). The change in $\mathrm{pH}$ of counter ion medium did not show any significant increase in the particle size.

\section{Table 2. Evaluation Parameters of PEC Beads}

\begin{tabular}{|c|c|c|}
\hline Code & $\begin{array}{l}\text { Particle size }(\mu \mathrm{m}) \\
\quad(\text { mean } \pm S D)\end{array}$ & $\begin{array}{l}\text { Percent drug entrapment } \\
\quad(\text { mean } \pm \text { SD) }\end{array}$ \\
\hline$C A C 1_{a}$ & $570.24 \pm 66.56$ & $91.22 \pm 1.05$ \\
\hline$C A C 1_{b}$ & $556.26 \pm 96.00$ & $93.58 \pm 0.82$ \\
\hline$C A C 2_{a}$ & $704.64 \pm 77.07$ & $94.14 \pm 1.33$ \\
\hline $\mathrm{CAC}_{\mathrm{b}}$ & $701.24 \pm 78.48$ & $94.85 \pm 1.56$ \\
\hline $\mathrm{CAC}_{\mathrm{a}}$ & $729.86 \pm 80.97$ & $96.46 \pm 0.60$ \\
\hline $\mathrm{CAC}_{\mathrm{b}}$ & $739.80 \pm 89.19$ & $97.08 \pm 0.73$ \\
\hline$C A A 1_{a}$ & $705.76 \pm 69.56$ & $91.07 \pm 1.52$ \\
\hline$C A A 1_{b}$ & $706.32 \pm 70.02$ & $93.21 \pm 1.25$ \\
\hline $\mathrm{CAA} 2_{\mathrm{a}}$ & $813.30 \pm 52.32$ & $91.90 \pm 0.78$ \\
\hline $\mathrm{CAA} 2_{b}$ & $819.60 \pm 59.13$ & $94.04 \pm 1.55$ \\
\hline $\mathrm{CAA3}_{\mathrm{a}}$ & $870.64 \pm 66.46$ & $94.71 \pm 1.40$ \\
\hline $\mathrm{CAAB}_{\mathrm{b}}$ & $865.72 \pm 84.45$ & $95.80 \pm 0.73$ \\
\hline $\mathrm{CC}_{\mathrm{a}}$ & $698.54 \pm 57.67$ & $86.97 \pm 1.90$ \\
\hline $\mathrm{CC}_{\mathrm{b}}$ & $700.26 \pm 66.52$ & $87.16 \pm 0.76$ \\
\hline $\mathrm{CC}_{\mathrm{a}}$ & $820.26 \pm 52.27$ & $91.23 \pm 0.35$ \\
\hline $\mathrm{CC} 2_{\mathrm{b}}$ & $835.80 \pm 54.07$ & $91.59 \pm 1.15$ \\
\hline $\mathrm{CC}_{\mathrm{a}}$ & $867.76 \pm 55.62$ & $93.24 \pm 2.45$ \\
\hline $\mathrm{CC}_{\mathrm{b}}$ & $896.18 \pm 53.98$ & $96.14 \pm 1.79$ \\
\hline $\mathrm{CK} 1_{\mathrm{a}}$ & $704.92 \pm 67.95$ & $80.01 \pm 0.59$ \\
\hline $\mathrm{CK} 1_{\mathrm{b}}$ & $683.74 \pm 30.34$ & $86.30 \pm 1.65$ \\
\hline $\mathrm{CK} 2_{\mathrm{a}}$ & $769.10 \pm 51.40$ & $87.69 \pm 1.04$ \\
\hline $\mathrm{CK} 2_{b}$ & $781.58 \pm 82.62$ & $88.20 \pm 1.46$ \\
\hline $\mathrm{CK}_{\mathrm{a}}$ & $871.42 \pm 69.26$ & $89.87 \pm 1.59$ \\
\hline $\mathrm{CK}_{\mathrm{b}}$ & $889.94 \pm 71.61$ & $90.98 \pm 1.63$ \\
\hline
\end{tabular}

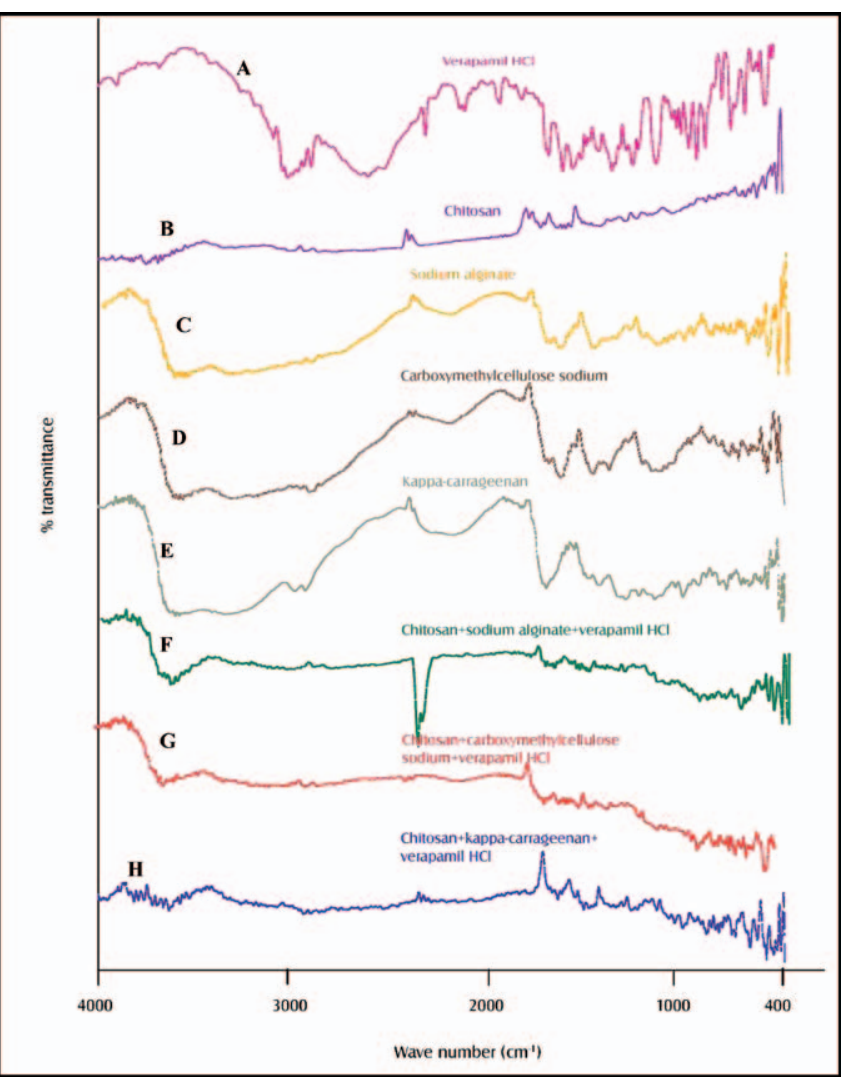

Figure 3. FTIR spectra of (A) VPL, (B) chitosan, (C) ALG, (D) CMC, (E) CAR, (F) $\mathrm{CH} / \mathrm{ALG}$ beads, (G) CH/CMC beads, and (H) CH/CAR beads.

\section{Drug Entrapment Efficiency}

The results of entrapment efficiency are presented in Table 2. The prepared PEC beads showed high entrapment efficiency in the range of $80.01-97.08 \%$, suggesting that the ionic gelation method was effective for the entrapment of VPL. The concentration of $\mathrm{CH}$ and the $\mathrm{pH}$ of the coagulation medium had an effect on the entrapment of VPL. With an increase in $\mathrm{CH}$ concentration and a change in the $\mathrm{pH}$ of coagulation medium, there was an increase in the entrapment efficiency of VPL. At higher concentrations of polymer and $\mathrm{pH}$ values corresponding to their ionized states, there will be an increase in both the charge density of the polymers, which leads to higher crosslinking, and ionic interaction. As a result, less drug was lost from the PEC beads during gelation, and hence a higher percent entrapment occurred $(11,12)$. The beads prepared with CAR showed less entrapment efficiency as compared with ALG and CMC because there was less cross-linking with low ionic interaction resulting in an increase in drug loss during the gelation process.

\section{Swelling Studies}

The swelling was measured by incubation and mass measurement method. The prepared PEC beads showed $\mathrm{pH}$-sensitive swelling behavior (Figure 4). The degree 


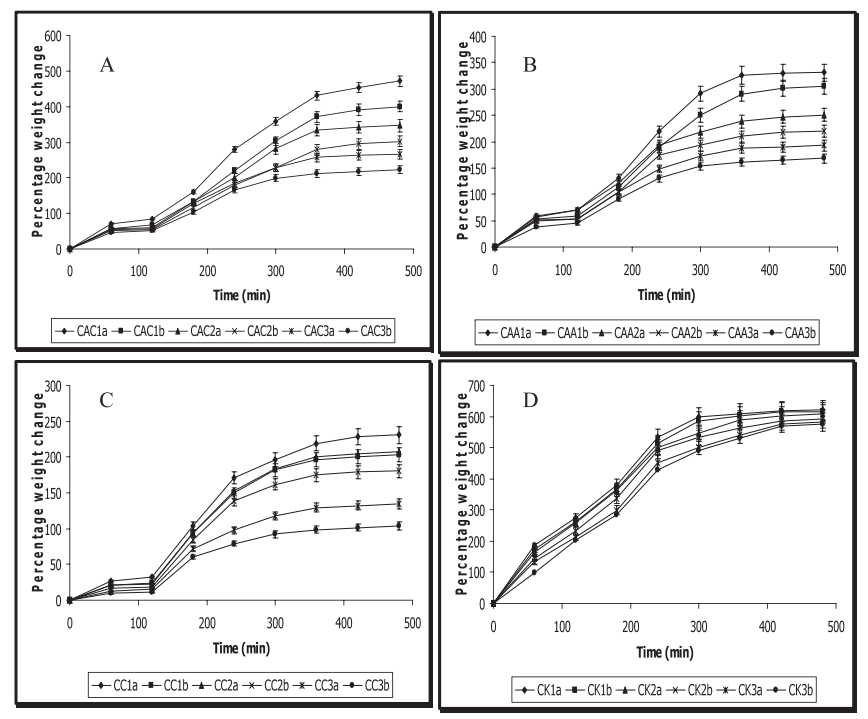

Figure 4. Swelling behavior of $\mathrm{CH} / \mathrm{ALG}$ beads formulated with (A) $\mathrm{CaCl}_{2}$, (B) $\mathrm{AlCl}_{3}$ (C) CH/CMC beads, and (D) CH/CAR beads.

of swelling was mainly affected by $\mathrm{pH}$ of the dissolution medium, type of anionic polymer, counterion, $\mathrm{pH}$ of counter ion medium, and concentration of $\mathrm{CH}$. All the beads show low swelling in $\mathrm{pH} 1.2 \mathrm{HCl}$ buffer, and after incubating the same beads in $\mathrm{pH} 7.4$ phosphate buffer, the degree of swelling increased. At pH 1.2, the amino $\left(-\mathrm{NH}_{3}{ }^{+}\right)$groups of chitosan were protonated, thereby increasing charge density, which interacts strongly with the carboxylic $\left(\mathrm{COO}^{-}\right)$groups of $\mathrm{ALG}, \mathrm{CMC}$, and sulphonic groups $\left(-\mathrm{SO}_{4}^{-}\right)$of CAR. This leads to the formation of stronger polyelectrolyte complexes, and hence the degree of swelling is reduced. At pH 7.4, the deprotonation of chitosan weakens the extent of ionic interactions, which leads to complex dissociation, and hence the degree of swelling is increased (11). The degree of swelling in $\mathrm{CH} / \mathrm{ALG}$ beads was affected by counter ions (Figures $4 A, B)$. The swelling of the beads prepared with $\mathrm{CaCl}_{2}$ was greater than that for beads prepared with $\mathrm{AlCl}_{3}$, which may be because the trivalent ions $\left(\mathrm{Al}^{3+}\right)$ increase the protonation of the carboxylic $\left(\mathrm{COO}^{-}\right)$groups and form a denser network. In addition, disc-shaped particles were formed, which restricts the entry of dissolution fluids into the beads. The degree of swelling in $\mathrm{CH} / \mathrm{CMC}$ beads was much less (Figure $4 \mathrm{C}$ ), indicating that strong ionic interaction occurred in the presence of $\mathrm{AlCl}_{3}$, which restricts the entry of dissolution fluids. The degree of swelling of CH/CAR beads was greater (Figure 4D) due to rapid dissociation of PEC in acidic as well as in alkaline $\mathrm{pH}$ because of weak ionic interactions. As the concentration of chitosan increased, the degree of swelling decreased due to decreased solubility of chitosan in $\mathrm{pH} 7.4$ dissolution medium (13). When the $\mathrm{pH}$ of the counterion medium was changed from $\mathrm{pH} 2$ to 4 , the degree of swelling decreased due to increased protonation of the

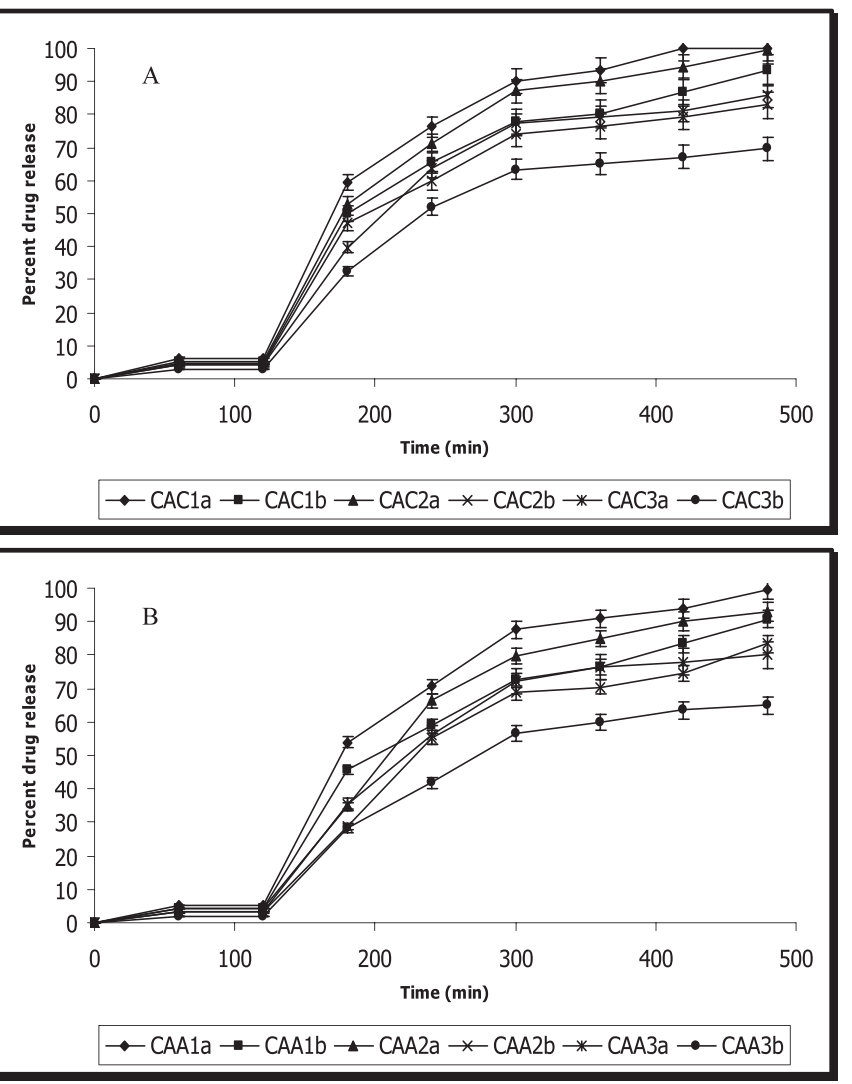

Figure 5. In vitro dissolution profiles of $C H / A L G$ beads formulated with (A) $\mathrm{CaCl}_{2}$ and (B) $\mathrm{AlCl}_{3}$.

amino $-\mathrm{NH}_{3}{ }^{+}$groups present, resulting in higher crosslinking of PEC and thus a stronger PEC membrane.

\section{In Vitro Dissolution Study}

The in vitro dissolution data for $\mathrm{CH} / \mathrm{ALG}, \mathrm{CH} / \mathrm{CMC}$, and $\mathrm{CH} / \mathrm{CAR}$ are presented in Figures 5 and 6 . The release of VPL from PEC beads was mainly affected by the dissolution medium, concentration of chitosan, type of anionic polymers used, $\mathrm{pH}$ of the coagulation medium, and counterion. The release of VPL was very slow in $\mathrm{pH} 1.2$ $\mathrm{HCl}$ buffer. After $2 \mathrm{~h}$, approximately $6.19 \%, 1.29 \%$, and $14.07 \%$ of drug was released from $\mathrm{CH} / \mathrm{ALG}, \mathrm{CH} / \mathrm{CMC}$, and $\mathrm{CH} / \mathrm{CAR}$ beads, respectively. At the acidic $\mathrm{pH}$ of the dissolution medium, the charge density of chitosan was sufficiently high, and the ionic interaction increased resulting in the formation of a much stronger network. In the second phase of the study using $\mathrm{pH} 7.4$ phosphate buffer, the release was rapid, and a maximum of $93.53 \%$, $80.35 \%$, and $97.46 \%$ of drug was released from $\mathrm{CH} / \mathrm{ALG}$, $\mathrm{CH} / \mathrm{CMC}$, and $\mathrm{CH} / \mathrm{CAR}$ beads, respectively, within $6 \mathrm{~h}$. The ionic interactions between chitosan and negatively charged polymers might have been reduced at $\mathrm{pH} 7.4$, forming a loose network with increased porous surface. This allows a large amount of dissolution medium along with counterions to enter into the PEC matrix. 


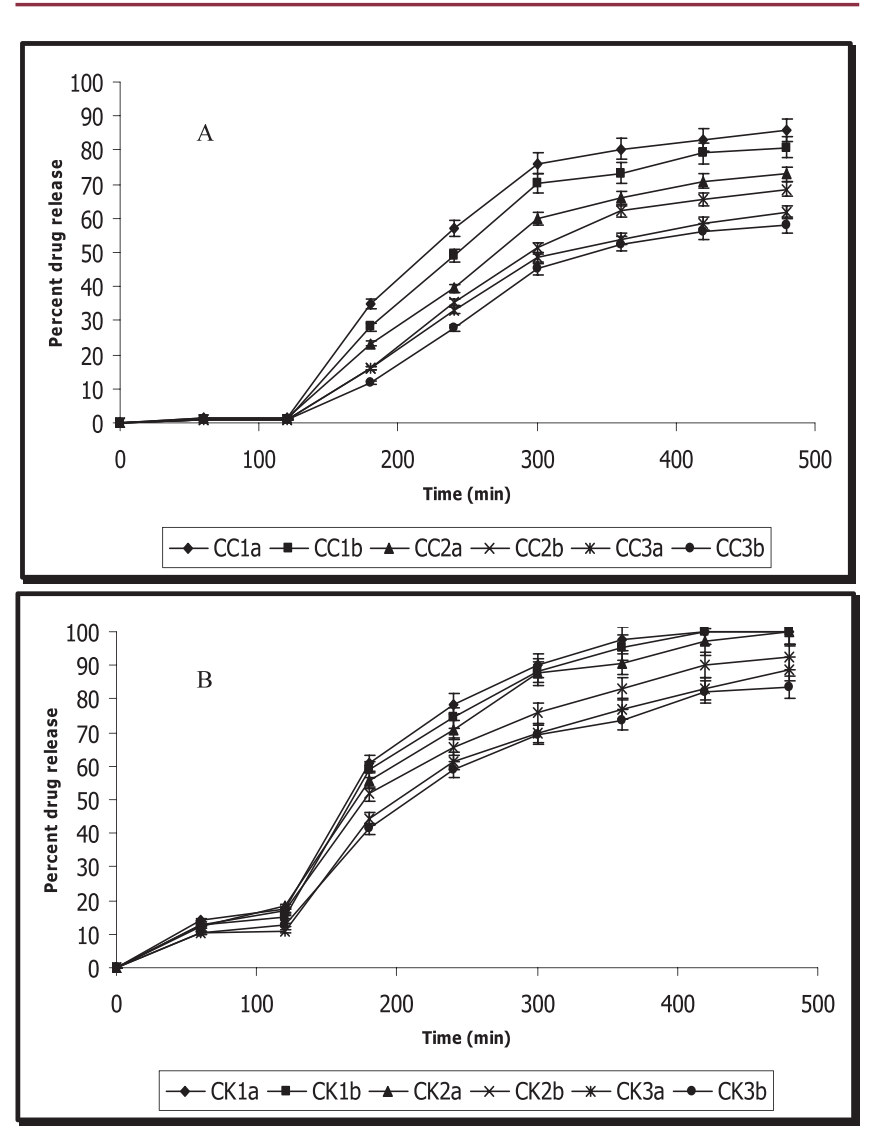

Figure 6. In vitro dissolution profiles of (A) $C H / C M C$ beads and (B) $C H / C A R$ beads.
Hence, in pH 7.4 phosphate buffer, rapid dissociation of the PEC membrane may occur leading to drug release with a burst effect (11). The $\mathrm{CH} / \mathrm{CMC}$ PEC beads showed sustained release of VPL (Figure 6A) due to formation of a stronger PEC membrane that restricts the easy entry of dissolution medium into the PEC matrix. The release of VPL from CH/CAR beads was very rapid (Figure 6B), because of the formation of a loose network of PEC which dissociates and disintegrates rapidly in phosphate buffer. With an increase in $\mathrm{CH}$ concentration, the interaction between the two polymers increased with the formation of a closer network, which showed a decrease in the diffusion of drug from the beads (14). When the $\mathrm{pH}$ of the coagulation medium was changed from $\mathrm{pH} 2$ to 4 , the charge density of the polymers increased. This resulted in more ionic interactions and the formation of a strong PEC membrane that did not swell or burst easily, thereby sustaining the release of VPL. The release data were subjected to the zero-order, first-order, Higuchi, Korsmeyer-Peppas, erosion, and Baker-Lonsdale models to establish the release mechanism and kinetics of drug release from PEC beads (Table 3). It was suggested that drug release followed first-order kinetics, and drug diffused out by erosion of the surface through dissociation of the PEC membrane. We have determined the release mechanism using the Korsmeyer-Peppas model. According to this model, $n$ values indicate the type of release mechanism. For spheres, values of $n$ between 0.45 and 0.85 are an indication of both diffusion-controlled and swelling-controlled release mechanisms (anomalous transport). Values greater than 0.85 and 1.0 indicate Case II and Super Case II transports, respectively, which relate to polymer relaxation. Because the values of $n$ obtained

Table 3. Regression Analysis and Correlation Coefficient Values According to Various Release Kinetics Models

\begin{tabular}{|c|c|c|c|c|c|c|c|c|c|c|c|c|c|}
\hline \multirow[b]{2}{*}{ Code } & \multicolumn{2}{|c|}{ Zero order } & \multicolumn{2}{|c|}{ First order } & \multicolumn{2}{|c|}{ Higuchi } & \multicolumn{3}{|c|}{ Korsmeyer-Peppas } & \multicolumn{2}{|c|}{ Erosion } & \multicolumn{2}{|c|}{ Baker-Lonsdale } \\
\hline & $r$ & SSR & $r$ & SSR & $r$ & SSR & $r$ & SSR & $n$ & $r$ & SSR & $r$ & SSR \\
\hline$C A C 1_{a}$ & 0.939 & 1770.20 & -0.962 & 0.108 & 0.920 & 2293.70 & 0.910 & 0.342 & 1.587 & -0.970 & 0.073 & 0.970 & 0.515 \\
\hline$C A C 2_{a}$ & 0.947 & 1438.70 & -0.938 & 0.518 & 0.921 & 2141.60 & 0.914 & 0.364 & 1.678 & -0.981 & 0.027 & 0.971 & 0.418 \\
\hline $\mathrm{CAC}_{\mathrm{a}}$ & 0.944 & 1143.20 & -0.972 & 0.051 & 0.916 & 1747.50 & 0.919 & 0.359 & 1.723 & -0.966 & 0.021 & 0.957 & 0.399 \\
\hline$C A A 1_{a}$ & 0.946 & 1470.70 & -0.932 & 0.588 & 0.920 & 2149.50 & 0.913 & 0.363 & 1.668 & -0.980 & 0.029 & 0.970 & 0.435 \\
\hline $\mathrm{CAA} 2_{\mathrm{a}}$ & 0.956 & 1094.20 & -0.978 & 0.070 & 0.915 & 2087.00 & 0.929 & 0.328 & 1.775 & -0.977 & 0.021 & 0.969 & 0.375 \\
\hline $\mathrm{CAA3}_{\mathrm{a}}$ & 0.950 & 958.35 & 0.969 & 0.044 & 0.914 & 1620.90 & 0.920 & 0.416 & 1.871 & -0.964 & 0.018 & 0.958 & 0.337 \\
\hline $\mathrm{CCl}_{\mathrm{a}}$ & 0.953 & 1054.80 & -0.972 & 0.055 & 0.908 & 1995.10 & 0.913 & 0.749 & 2.400 & -0.969 & 0.020 & 0.962 & 0.371 \\
\hline $\mathrm{CC}_{\mathrm{a}}$ & 0.968 & 501.25 & 0.973 & 0.024 & 0.906 & 1406.00 & 0.932 & 0.490 & 2.220 & -0.973 & 0.010 & 0.971 & 0.176 \\
\hline $\mathrm{CC}_{\mathrm{a}}$ & 0.969 & 339.98 & -0.973 & 0.013 & 0.902 & 1034.80 & 0.933 & 0.555 & 2.398 & -0.973 & 0.006 & 0.971 & 0.113 \\
\hline $\mathrm{CK} 1_{\mathrm{a}}$ & 0.947 & 1369.70 & -0.959 & 0.215 & 0.944 & 1452.30 & 0.942 & 0.097 & 1.087 & -0.980 & 0.049 & 0.976 & 0.391 \\
\hline $\mathrm{CK} 2_{\mathrm{a}}$ & 0.963 & 910.92 & -0.967 & 0.137 & 0.951 & 1201.80 & 0.962 & 0.067 & 1.122 & -0.974 & 0.046 & 0.986 & 0.203 \\
\hline $\mathrm{CK}_{\mathrm{a}}$ & 0.969 & 579.23 & -0.987 & 0.024 & 0.944 & 1031.80 & 0.940 & 0.122 & 1.187 & -0.988 & 0.007 & 0.981 & 0.159 \\
\hline
\end{tabular}

$r$ : regression coefficient

SSR: sum of squares of residual

n: slope 
for all the formulations are greater than 1.0, the release mechanism is Super Case-II transport.

\section{CONCLUSIONS}

PEC beads were successfully prepared by an ionic gelation method using positively charged chitosan and negatively charged sodium alginate, carboxymethylcellulose sodium, and k-carrageenan for the prolonged release of the water-soluble drug, VPL. The SEM study confirmed the shape of the beads that were prepared by changing the counterion and $\mathrm{pH}$ of the coagulation medium. The particle size range was 556-896 $\mu \mathrm{m}$, and drug entrapment efficiency was as high as $97 \%$. The beads showed $\mathrm{pH}$-sensitive swelling with lower swelling in $\mathrm{pH}$ 1.2 hydrochloric acid buffer and higher swelling in $\mathrm{pH} 7.4$ phosphate buffer. The in vitro release of VPL was very slow in hydrochloric acid buffer as compared with phosphate buffer. Among the anionic polymers used, carboxymethylcellulose sodium showed prolonged release of drug more efficiently. Hence, this study indicates that the proper selection of reaction $\mathrm{pH}$, counter ions, and concentration of chitosan can result in the formation of stable PEC beads for the prolonged release of highly water-soluble drugs.

\section{ACKNOWLEDGMENTS}

The authors are thankful to the Principal and Management of Luqman College of Pharmacy, Gulbarga (India), for providing all the necessary facilities to carry out this research.

\section{REFERENCES}

1. Bhattarai, N.; Gunn, J. J.; Zhang, M. Chitosan-based hydrogels for controlled, localized drug delivery. Adv. Drug Deliv. Rev. 2010, 62 (1), 83-99.

2. Naidu, V. G. M.; Madhusudhana, K.; Sashidhar, R. B.; Ramakrishna, S.; Khar, R. K.; Ahmed, F. J.; Diwan, P. V. Polyelectrolyte complexes of gum kondagogu and chitosan, as diclofenac carriers. Carbohydr. Polym. 2009, 76 (3), 464-471.

3. Felt, O.; Buri, P.; Gurny, R. Chitosan: A Unique Polysaccharide for Drug Delivery. Drug Dev. Ind. Pharm. 1998, 24 (11), 979-993.

4. Lankalapalli, L.; Kolapalli, V. R. M. Polyelectrolyte Complexes: A Review of their Applicability in Drug
Delivery Technology. Indian J. Pharm. Sci. 2009, 71 (5), 481-487.

5. Berger, J.; Reist, M.; Mayer, J. M.; Felt, O.; Peppas, N. A.; Gurny, R. Structure and interactions in covalently and ionically crosslinked chitosan hydrogels for biomedical applications. Eur. J. Pharm. Biopharm. 2004, 57 (1), 19-34.

6. Long, D. D.; VanLuyen, D. ChitosanCarboxymethylcellulose Hydrogels as Supports for Cell Immobilization. J. Macromol. Sci. A 1996, 33 (12), 1875-1884.

7. Wang, H.; Li, W.; Lu, Y.; Wang, Z. Studies on chitosan and poly(acrylic acid) Interpolymer Complex I. Preparation, structure, $\mathrm{pH}$-sensitivity, and salt sensitivity of complex-forming poly(acrylic acid): Chitosan semi-interpenetrating polymer network. J. Appl. Polym. Sci. 1997, 65 (8), 1445-1450.

8. Takahashi, T.; Takayama, K.; Machida, Y.; Nagai, T. Characteristics of Polyion Complexes of Chitosan with Sodium Alginate and Sodium Polyacrylate. Int. J. Pharm. 1990, 61 (1-2), 35-41.

9. Lee, J. W.; Kim, S. Y.; Kim, S. S.; Lee, Y. M.; Lee, K. H.; Kim, S. J. Synthesis and Characteristics of Interpenetrating Polymer Network Hydrogel Composed of Chitosan and Poly(acrylic acid). J. Appl. Polym. Sci. 1999, 73 (1), 113-120.

10. Hamman, J. H. Chitosan Based Polyelectrolyte Complexes as Potential Carrier Materials in Drug Delivery Systems. Mar. Drugs 2010, 8 (4), 1305-1322.

11. Patel, A.; Moin, M.; Shah, D.; Patel, V. Development and In Vivo Floating Behavior of Verapamil $\mathrm{HCl}$ Intragastric Floating Tablets. AAPS PharmSciTech 2009, 10 (1), 310-315.

12. Kunte, S.; Tandale, P. Fast dissolving strips: A novel approach for the delivery of verapamil. J. Pharm. Bioallied Sci. 2010, 2 (4), 325-328.

13. Chandira, M.; Debjit, M.; Chiranjib, K.; Jayakar, B. Formulation, design and development of buccoadheshive tablets of verapamil hydrochloride. Int. J. PharmTech Res. 2009, 1 (4), 1663-1677.

14. Daly, M. M.; Knorr, D. Chitosan-Alginate Complex Coacervate Capsules: Effects of Calcium Chloride, Plasticizers, and Polyelectrolytes on Mechanical Stability. Biotechnol. Prog. 1988, 4 (2), 76-81. 